\title{
Uropathogen antibiotic resistance in adult women presenting to family physicians with acute uncomplicated cystitis
}

\author{
Warren J Mclsaac MD MSc CCFP, Tony Mazzulli MD FRCPC, Rahim Moineddin PhD, \\ Janet Raboud PhD, Susan Ross PhD
}

WJ McIsaac, T Mazzulli, R Moineddin, J Raboud, S Ross. Uropathogen antibiotic resistance in adult women presenting to family physicians with acute uncomplicated cystitis. Can J Infect Dis Med Microbiol 2004;15(5):266-270.

BACKGROUND: Increasing rates of trimethoprim-sulfamethoxazole (TMP-SMX) resistance among uropathogens have raised concerns about its continued role in empirical treatment of acute uncomplicated cystitis in adult women.

OBJECTIVES: To determine current rates of antibiotic resistance among uropathogens in the community.

METHOD: Urine culture reports from adult women with symptoms of cystitis attending the offices of family physicians from across Canada were examined. Antibiotic sensitivities and the total number of antibiotics an organism was resistant to was determined. RESULTS: In 446 women, 235 (61.4\%) positive urine cultures were identified. Of these, $38.2 \%$ were resistant to at least one antibiotic and $21.5 \%$ were resistant to two or more antibiotics. The rate of ampicillin resistance was $34.1 \%$. For TMP-SMX, resistance was reported in $10.8 \%$ of samples. Antibiotic resistance was higher in British Columbia (55\%) and western provinces (48\%), compared with Ontario (33.3\%) and the eastern provinces $(26.3 \%, \mathrm{P}=0.04$, Fisher's exact test). Multidrug resistance was also higher in western Canada (33.9\%) than in eastern Canada (16.6\%, P=0.007).

CONCLUSIONS: TMP-SMX resistance in Canada remains within current recommended guidelines, allowing for its continued use as a first line empirical treatment for acute cystitis in adult women. The reasons for higher rates of antibiotic resistance in western Canada merit further study.

Key Words: Antibiotic resistance; Cystitis; Uropathogens

A ntibiotic resistance among uropathogens has increased lover the past 30 years (1-3). Between 1971 and 1992, ampicillin resistance increased from $12 \%$ to $43 \%$ in Britain (1). In the United States, ampicillin resistance was $29 \%$ in 1992 (2). This resistance, however, had increased to 38\% by 1996 (2). In 1998, the rate of ampicillin resistance in Canada, based on a sample of 2000 outpatients, was $41 \%$ (3).

In the community, acute uncomplicated cystitis in adult women accounts for the majority of uropathogen infections (4). Most infections are caused by Escherichia coli (4). In North

\section{Résistance des uropathogènes aux antibio- tiques chez des femmes consultant en médecine familiale pour une cystite aiguë non compliquée}

\begin{abstract}
HISTORIQUE : Les taux croissants de résistance des uropathogènes à l'endroit du triméthoprime-sulfaméthoxazole (TMP SMX) suscitent l'inquiétude et on s'interroge à présent sur leur rôle dans le traitement empirique de la cystite aiguë non compliquée chez la femme.

OBJECTIF : Déterminer les taux actuels de résistance aux antibiotiques des uropathogènes dans la collectivité

MÉTHODE : Les rapports de cultures d'urine de femmes adultes présentant des symptômes de cystite vues en médecine familiale en provenance d'un peu partout au Canada ont fait l'objet d'une analyse. Les antibiogrammes et le nombre total d'antibiotiques auxquels les agents pathogènes étaient résistants ont été déterminés.

RÉSULTATS : Chez 446 femmes, on a dénombré 235 (61,4\%) cultures d'urine positives. Parmi ces dernières, $38,2 \%$ se sont révélées résistantes à au moins un antibiotique et $21,5 \%$, à deux antibiotiques ou plus. Le taux de résistance à l'ampicilline était de 34,1\%. Dans le cas du TMP SMX, la résistance a été observée dans 10,8 \% des échantillons. C'est en Colombie-Britannique ( $55 \%$ ) et dans les provinces de l'Ouest (48\%) que la résistance aux antibiotiques a été la plus forte, comparativement à l'Ontario (33,3\%) et aux provinces de l'Est (26,3\%, p = 0,04, test exact de Fisher). La multirésistance a également été plus élevée dans l'Ouest du Canada (33,9\%) que dans l'Est $(16,6 \%, \mathrm{p}=0,007)$.

CONCLUSIONS : La résistance au TMP-SMX au Canada reste à l'intérieur des limites acceptables selon les directives en vigueur. Nous pouvons donc continuer de le prescrire en traitement empirique de première intention pour la cystite aiguë chez la femme. Il faudra approfondir la recherche pour découvrir les causes des taux de résistance aux antibiotiques plus élevés observés dans l'Ouest du Canada.
\end{abstract}

America, trimethoprim-sulfamethoxazole (TMP-SMX) is recommended for empirical treatment where rates of TMPSMX resistance among E coli are less than 20\% (4,5). Recently, TMP-SMX resistance rates as high as $22 \%$ have been reported in some areas of the United States (6).

In Canada, a 1998 study found that the rate of TMP-SMX resistance was $19.2 \%$ (3). However, this study involved outpatients from tertiary care hospitals and included men, women and children. In contrast, a 1997 community-based study of family physician offices in southern Ontario found that only 
$8 \%$ of E coli were resistant to TMP-SMX (7). Geographic variation in resistance has been observed in the United States $(8,9)$, but not in Canada (3); this may account for the differences between the two studies. Alternatively, the higher comorbidity of hospital outpatients may result in more frequent hospitalization with an increased risk of acquiring antimicrobial resistance (3).

If TMP-SMX resistance in Canada is approaching 20\% (3), this raises questions about the continued use of TMP-SMX as a first line empirical treatment in uncomplicated cystitis $(2-4,8-10)$. To estimate current rates of TMP-SMX resistance in the community, a study of acute cystitis was conducted in family practice offices across Canada.

\section{METHOD}

A random sample of family physicians from across Canada was contacted by mail. All physicians were members of the College of Family Physicians of Canada and engaged in fulltime clinical family practice. Participants were asked to assess women 16 years of age or older presenting with new urinary tract symptoms where acute uncomplicated cystitis was considered as a possible diagnosis. Those considered ineligible for the study included children, men, pregnant women, nursing home residents, patients on antibiotics or unable to read English, immunocompromised patients and those with known underlying renal tract abnormalities or requiring catheters.

Physicians completed a clinical assessment form and provided women with an information sheet about the study. Consenting women were questioned about their symptoms and asked to allow a copy of the urine culture report to be sent to the study centre. Collected urine samples were sent to the physician's community laboratory (where the physician normally submitted samples for testing). Laboratories were asked to provide a copy of the culture result and bill the study for the cost of all urine cultures.

A number of community-based laboratories from across the country participated, processing the urine cultures in their usual manner. In some regions, hospital-based laboratories provided this service. Urine cultures were considered to be positive for infection if the colony count for a single organism was greater than $10^{8} \mathrm{CFU} / \mathrm{L}$ or if the colony count was between $10^{6}$ and $10^{8}$ of a known pathogenic organism $(2,4,5)$. Cultures with three or more organisms suggestive of contamination were considered to be negative.

For positive cultures, the antibiotic sensitivity reports were examined to determine if an isolate was resistant to any antibiotics. Where sensitivity to a particular antibiotic was classified as intermediate, the organism was considered to be sensitive. The total number of antibiotics a given organism was resistant to was also determined. Because all labs did not test for sensitivities to the same antibiotics, the denominators for some antibiotics were less than the total number of samples.

Analysis was carried out using SAS version 8.2 (SAS Institute Inc, USA). Fisher's exact test was used for comparing proportions because a number of cells had counts of less than five. Point estimates and CIs were calculated based on exact permutation distributions because small cell counts made maximum likelihood estimates inappropriate (11). Ethics approval was obtained from the Mount Sinai Hospital Research Ethics Board.

\section{RESULTS}

A total of 420 family physicians agreed to participate in the study. Two hundred forty-six (58.6\%) physicians submitted

\begin{tabular}{|c|c|c|}
\hline Characteristic & $\mathbf{n}$ & $\%$ \\
\hline Total sample & 446 & 100.0 \\
\hline \multicolumn{3}{|l|}{ Province $(n=445)$} \\
\hline British Columbia & 74 & 16.6 \\
\hline Alberta & 41 & 9.2 \\
\hline Saskatchewan & 14 & 3.2 \\
\hline Manitoba & 14 & 3.2 \\
\hline Ontario & 255 & 57.3 \\
\hline Quebec & 9 & 2.0 \\
\hline New Brunswick & 11 & 2.5 \\
\hline Nova Scotia & 14 & 3.2 \\
\hline Prince Edward Island & 4 & 1.0 \\
\hline Newfoundland & 9 & 2.0 \\
\hline \multicolumn{3}{|l|}{ Age (years) } \\
\hline $16-44$ & 248 & 55.6 \\
\hline $45-64$ & 119 & 26.7 \\
\hline 65 and older & 79 & 17.7 \\
\hline \multicolumn{3}{|c|}{ Previous urinary tract infection $(n=410)$} \\
\hline None & 54 & 13.2 \\
\hline One & 96 & 23.4 \\
\hline Two or more & 260 & 63.4 \\
\hline Culture-positive $(n=383)$ & 235 & 61.4 \\
\hline
\end{tabular}

clinical data for up to two women per practice. Physicians from all 10 provinces participated, with the majority from Ontario and British Columbia (Table 1). There were 42 different laboratories that provided culture reports between April 2002 and November 2002.

A total of 446 women, ranging in age from 16 to 99 years (mean age 44.0 years), were assessed. Two-thirds of the women reported two or more previous episodes of cystitis (Table 1). Urine culture reports were available for 383 women $(85.9 \%)$. Of these, there were 235 positive urine cultures $(61.4 \%)$, and sensitivity reports were available for 228 of 235 positive cultures $(97.0 \%)$. The most common organism isolated was $E$ coli (Table 2).

Of the 235 positive cultures, $38.2 \%$ were resistant to at least one antibiotic and $21.5 \%$ were resistant to two or more antibiotics (Table 2). The rate of antibiotic resistance was highest for ampicillin $(34.1 \% ; 95 \%$ CI $27.8 \%$ to $40.8 \%)$. The rate of resistance to TMP-SMX was $10.8 \%$ (95\% CI $7.0 \%$ to $15.8 \%$ ). Fewer than $5 \%$ of isolates were resistant to nitrofurantoin or quinolones. Among E coli isolates, 56 of 189 (29.6\%) were resistant to ampicillin, 20 of $183(10.9 \%)$ were resistant to TMP-SMX, two of 187 (1.1\%) were resistant to nitrofurantoin and two of $178(1.1 \%)$ were resistant to quinolones.

To examine geographic variation, and due to the small numbers of positive cultures, provinces were grouped into four regions (British Columbia, Ontario, the western provinces [Alberta, Saskatchewan, Manitoba] and the eastern provinces [Quebec, New Brunswick, Nova Scotia, Newfoundland and Prince Edward Island]). Women who lived in British Columbia or a western province, who were 65 years of age or older, or had an infection with an organism other than $E$ coli, were more likely to have an antibiotic-resistant infection (Table 3).

Residence in British Columbia or a western province was the only factor associated with having a greater likelihood of 
TABLE 2

Distribution of bacterial organisms and antibiotic resistance in positive urine cultures from adult women with uncomplicated urinary tract infections

\begin{tabular}{lcc}
\hline Characteristic & $\mathbf{n}$ & $\%$ \\
\hline Positive urine cultures & 235 & 100.0 \\
Organisms $(\mathrm{n}=234)$ & & \\
$\quad$ Escherichia coli & 190 & 81.2 \\
Klebsiella pneumoniae & 9 & 3.9 \\
Staphylococcus saprophyticus & 9 & 3.9 \\
Enterococcus species & 8 & 3.4 \\
Proteus mirabilis & 3 & 1.3 \\
Other* & 15 & 6.4 \\
Number of antibiotics resistant to $(\mathrm{n}=228)$ & & \\
None & 141 & 61.8 \\
One & 38 & 16.7 \\
Two & 25 & 11.0 \\
Three & 13 & 5.7 \\
Four & 8 & 3.5 \\
Five & 3 & 1.3 \\
Type of antibiotic resistance & \\
Ampicillin $(\mathrm{n}=217)$ & & \\
Sulfonamides $(\mathrm{n}=51)$ & 74 & 34.1 \\
Trimethoprim-sulfamethoxazole $(\mathrm{n}=213)$ & 12 & 23.5 \\
Cephalosporins $(\mathrm{n}=207)$ & 23 & 10.8 \\
Nitrofurantoin $(\mathrm{n}=222)$ & 15 & 7.3 \\
Quinolones $(\mathrm{n}=209)$ & 7 & 3.2 \\
\hline
\end{tabular}

*Other includes three or fewer of coagulase-negative staphylococcus, group $B$ streptococcus, Enterobacter aerogenes, Pseudomonas species, Klebsiella oxytoca; ' not all samples tested for each antibiotic listed; ' $n$ ' indicates number of culture reports reporting sensitivity to that antibiotic

having a multidrug-resistant urinary tract infection (UTI) (Table 3). The rate of multidrug antibiotic resistance among women in British Columbia and the western provinces was $33.9 \%$ (22 of 65 women), compared with $16.7 \%$ (27 of 163 women) in Ontario and the eastern provinces $(\mathrm{P}=0.007$, Fisher's exact test).

To assess whether other factors associated with resistance proportion of women 65 years of age or older, history of previous UTIs, type of organisms isolated - accounted for the observed geographic variation in resistance, each factor was examined by region. The differences in antibiotic resistance were primarily due to higher ampicillin resistance rates in western Canada (Table 4). There were no differences in the rates of TMP-SMX resistance $(\mathrm{P}=0.12)$. No differences were identified between regions in terms of the rate of positive cultures, the history of previous UTI in women, the proportion of women 65 and older or the occurrence of non-E coli infections.

The distribution of non-E coli organisms in each region that were $100 \%$ resistant to ampicillin (Klebsiella pneumoniae, Staphylococcus saprophyticus, Enterobacter aerogenes, coagulasenegative Staphylococcus, Klebsiella oxytoca) was similar in British Columbia (six of 40, 15.0\%), Ontario (16 of 145, $11.0 \%$ ) and the western provinces (four of $28,14.3 \%$ ). None of these organisms were isolated in eastern provinces. The proportion of women that were prescribed antibiotics was also similar among regions $(\mathrm{P}=0.19)$.

After adjustment for other factors associated with resistance (age, previous UTI, organism), women who lived in British Columbia or a western province remained more likely to have an antibiotic-resistant infection or an infection resistant to two
TABLE 3

Factors associated with antibiotic resistance in adult women with uncomplicated urinary tract infections

\begin{tabular}{|c|c|c|c|}
\hline Characteristic & $\mathbf{n}$ & $\begin{array}{l}\text { Antibitiotic- } \\
\text { resistant }(\%)^{*}\end{array}$ & $\begin{array}{c}\text { Multidrug }{ }^{\ddagger} \\
\text { resistance (\%) }\end{array}$ \\
\hline Total sample & 228 & $87(38.2)$ & $49(21.5)$ \\
\hline \multicolumn{4}{|l|}{ Region } \\
\hline British Columbia & 40 & $22(55.0)$ & $15(37.5)$ \\
\hline Western provinces & 25 & $12(48.0)$ & $7(28.0)$ \\
\hline Ontario & 144 & $48(33.3)$ & $24(16.7)$ \\
\hline Eastern provinces & 19 & $5(26.3)^{\dagger}$ & $3(15.8)^{\dagger}$ \\
\hline \multicolumn{4}{|l|}{ Patient age } \\
\hline 16 to 64 & 183 & $63(34.4)$ & $35(19.1)$ \\
\hline 65 and older & 45 & $24(53.3)^{\dagger}$ & $14(31.1)$ \\
\hline \multicolumn{4}{|c|}{ Previous urinary tract infections } \\
\hline None & 34 & $8(23.5)$ & $3(8.8)$ \\
\hline One & 51 & $15(31.4)$ & $10(19.6)$ \\
\hline Two or more & 124 & $52(41.9)$ & $29(23.4)$ \\
\hline \multicolumn{4}{|l|}{ Organism } \\
\hline Escherichia coli & 189 & $64(33.9)$ & $38(20.1)$ \\
\hline Other & 39 & $23(59.0)^{\dagger}$ & $11(28.2)$ \\
\hline
\end{tabular}

${ }^{*}$ Defined as resistance to at least one antibiotic; ${ }^{\ddagger}$ defined as resistance to two or more antibiotics; ${ }^{\dagger} P<0.05$, Fisher's exact test

TABLE 4

Comparison of antibiotic-specific resistance and factors associated with antibiotic resistance by region

\begin{tabular}{|c|c|c|c|c|}
\hline & BC & West & Ontario & East \\
\hline \multicolumn{5}{|l|}{ Type of resistance } \\
\hline \multirow[t]{2}{*}{ Overall (\%) } & 55.0 & 48.0 & 33.3 & $26.3^{*}$ \\
\hline & $(22 / 40)$ & $(12 / 25)$ & $(48 / 144)$ & $(5 / 19)$ \\
\hline \multirow[t]{2}{*}{ Ampicillin (\%) } & 47.5 & 52.2 & 29.6 & $15.8^{*}$ \\
\hline & $(19 / 40)$ & $(12 / 23)$ & $(40 / 135)$ & $(3 / 19)$ \\
\hline \multirow[t]{2}{*}{ TMP-SMX (\%) } & 10.8 & 23.8 & 10.2 & 0.0 \\
\hline & $(4 / 37)$ & $(5 / 21)$ & $(14 / 137)$ & $(0 / 18)$ \\
\hline \multirow[t]{2}{*}{ Quinolone (\%) } & 0.0 & 0.0 & 2.3 & 6.7 \\
\hline & $(0 / 39)$ & $(0 / 23)$ & $(3 / 132)$ & $(1 / 15)$ \\
\hline \multicolumn{5}{|c|}{ Factors related to resistance } \\
\hline \multirow[t]{2}{*}{ Prescribing rate (\%) } & 84.3 & 93.9 & 84.9 & 91.1 \\
\hline & $(59 / 70)$ & $(61 / 65)$ & $(203 / 239)$ & $(41 / 45)$ \\
\hline \multirow[t]{2}{*}{ Positive culture (\%) } & 65.1 & 50.0 & 63.3 & 60.0 \\
\hline & $(41 / 63)$ & $(28 / 56)$ & $(145 / 230)$ & $(21 / 34)$ \\
\hline \multirow[t]{2}{*}{ Patient age $65+(\%)$} & 20.3 & 17.4 & 16.9 & 19.2 \\
\hline & $(15 / 74)$ & $(12 / 69)$ & $(43 / 255)$ & $(9 / 47)$ \\
\hline \multirow[t]{2}{*}{$>2$ previous UTI (\%) } & 55.7 & 67.2 & 63.5 & 70.0 \\
\hline & $(39 / 70)$ & $(43 / 64)$ & $(148 / 233)$ & $(30 / 42)$ \\
\hline \multicolumn{5}{|l|}{ non-Escherichia } \\
\hline \multirow[t]{2}{*}{ coli (\%) } & 17.5 & 21.4 & 18.6 & 19.1 \\
\hline & $(7 / 40)$ & $(6 / 28)$ & $(27 / 145)$ & $(4 / 21)$ \\
\hline
\end{tabular}

${ }^{*} P<0.05$, Fisher's exact test. BC British Columbia; TMP-SMX Trimethoprimsulfamethoxazole; UTI Urinary tract infection

or more antibiotics. Women from Ontario were 64\% less likely to have an antibiotic-resistant UTI (adjusted OR 0.36, 95\% CI 0.19 to 0.89 ) and $67 \%$ less likely to have a multidrugresistant infection (adjusted OR 0.33, 95\% CI 0.13 to 0.85). An antibiotic-resistant UTI was also less likely in eastern provinces compared with British Columbia (adjusted OR 0.20, $95 \%$ CI 0.04 to 0.85). There was no difference in resistance between western provinces and British Columbia (adjusted OR $0.72,95 \%$ CI 0.22 to 2.38 ). 


\section{DISCUSSION}

Almost $40 \%$ of adult women in Canada with communityacquired cystitis had an infection resistant to at least one antibiotic. Furthermore, one of five women were resistant to multiple antibiotic drugs. Although previous studies have not identified geographic variation in antibiotic resistance in Canada (3), the present study found that antibiotic-resistant and multidrug-resistant UTIs were more common in western Canada.

The level of antibiotic resistance in Canadian women with community-acquired UTI was lower than reported from some countries. Ampicillin resistance among E coli was 30\% in the present study, compared with $33 \%$ to $40 \%$ in the United States (9) and 49\% in the United Kingdom (12). The rate of TMPSMX-resistant E coli was $11 \%$ in Canadian women compared with $16 \%$ to $18 \%$ in the United States and $29 \%$ in Israel $(2,9,13)$. These differences may be due in part to the populations studied. Other studies reporting higher rates of TMPSMX resistance were based on cultures from patients attending hospital outpatient departments $(3,14)$.

In contrast, resistance rates reported from other general practice settings were similar to those in the current study $(15,16)$. The rate of ampicillin resistance in adult women attending general practitioners in New Zealand was 29\%; TMP-SMX resistance was 10\% (15). In Norway and Belgium, resistance to cotrimoxazole in urine samples from dysuric women in general practice was $14 \%$ and $12 \%$, respectively (16). The present study found a similar $11 \%$ rate of TMP-SMX resistance. This is less than the $19 \%$ resistance rate in outpatients attending Canadian tertiary care hospitals (3), suggesting that resistance rates based on hospital outpatients may overestimate resistance in the community.

Increasing rates of TMP-SMX resistance have led to questions about the continued use of TMP-SMX as a first line empirical treatment in cystitis $(2-4,8-10)$. Current guidelines recommend TMP-SMX as appropriate when resistance levels are below 20\% (5). Although resistance rates in hospital outpatients are approaching this level (3), the rate of TMP-SMX resistance in community-acquired cystitis in Canada is within current recommended guidelines, allowing for the continued use of TMP-SMX as a first line empirical agent (5).

Uropathogen antibiotic resistance levels were higher in western Canada than in eastern Canada. This is consistent with observations from the United States $(8,9)$. A large American study of adult women found that resistance was highest in the western and southern regions and lowest in the north-eastern region (9). Multidrug-resistant E coli follow a similar distribution (8). While the reasons for this geographic variation are unknown (9), a number of possibilities have been suggested, including the introduction of multidrug-resistant E coli organisms from an outside source and differences in antibiotic use among regions resulting in varying selective pressure for resistance $(6,9)$.

Although there was no variation in antibiotic prescribing patterns between regions in the present study, total antibiotic use was not determined. Respiratory tract infections account for the majority of antibiotics prescribed (17). It is possible that regional differences in total antibiotic use account for the observed geographic variation (18). There were also limited numbers of urine culture reports from Quebec and the eastern provinces. The low rate of non- $E$ coli organisms resistant to ampicillin in eastern Canada may be a chance finding due to small numbers.

However, the observed differences in resistance between Ontario and the western provinces are greater than expected by chance. Although a previous Canadian study did not identify geographic differences in antibiotic resistance among uropathogens, Ontario and Maritime provinces were not included in the study (3). In the present study, these two regions accounted for the greatest differences with British Columbia. To confirm whether geographic variation in uropathogen resistance exists in Canada, a larger study is needed.

A number of different laboratories, both private and hospital-based, participated in the present study. There was no attempt made to standardize laboratory procedures. This may have resulted in greater variation in resistance rates. However, systematic differences in methods among laboratories in western Canada compared with eastern Canada seem unlikely to account for the differences. Another possibility is regional differences in the use of urine cultures in women with recurrent infections or those recently treated with antibiotics at higher risk for resistance. However, British Columbia had the fewest women reporting two or more previous urine infections.

TMP-SMX resistance among adult, nonpregnant women with acute uncomplicated cystitis presenting to family physicians remains low (within prescribed guidelines) in Canada, allowing for the continued use of TMP-SMX as a first line empirical agent (5). The present study suggests that geographic variation in uropathogen antibiotic resistance exists in Canada; this notion should be confirmed in a larger study.

ACKNOWLEDGEMENT: Financial support: CIHR grant no. MOP-53290, Originating Institution: Mount Sinai Hospital, Toronto, Ontario

\section{REFERENCES}

1. Gruneberg RN. Changes in urinary pathogens and their antibiotic sensitivities, 1971-1992. J Antimcrob Chemother 1994;33(Suppl A):1-8.

2. Gupta K, Scholes D, Stamm WE. Increasing prevalence of antimicrobial resistance among uropathogens causing acute uncomplicated cystitis in women. JAMA 1999;281:736-8.

3. Zhanel GG, Karlowsky JA, Harding GKM, et al. A Canadian national surveillance study of urinary tract isolates from outpatients: Comparison of the activities of trimethoprimsulfamethoxazole, ampicillin, mecillinam, nitrofurantoin and ciprofloxacin. Antimicrob Agents Chemother 2000;44:1089-92.

4. Fihn SD. Clinical practice. Acute uncomplicated urinary tract infection in women. N Engl J Med 2003;349:259-66.

5. Warren JW, Abrutyn E, Hebel JR, Johnson JR, Schaeffer AJ,
Stamm WE. Guidelines for antimicrobial treatment of uncomplicated acute bacterial cystitis and acute pyleonephritis in women. Clin Infect Dis 1999;29:745-58.

6. Manges AR, Johnson JR, Foxman B, O'Bryan TT, Fullerton KE, Riley LW. Widespread distribution of urinary tract infections caused by a multidrug-resistant Escherichia coli clonal group. N Engl J Med 2001;345:1007-13.

7. Mazzulli T, Skulnick M, Small G, et al. Susceptibility of community Gram-negative urinary tract isolates to mecillinam and other oral agents. Can J Infect Dis 2001;12:289-92.

8. Sahm DF, Thornsberry C, Mayfield DC, Jones ME, Karlowsky JA. Multidrug-resistant urinary tract isolates of Escherichia coli:

Prevalence and patient demographics in the United States in 2000. Antimicrob Agents Chemother 2001;45:1402-6. 
9. Gupta K, Sahm DF, Mayfield D, Stamm WE. Antimicrobial resistance among uropathogens that cause community-acquired urinary tract infections in women: A nationwide analysis. Clin Infect Dis 2001;38:89-94.

10. Nicolle LE. Empirical treatment of acute cystitis in women. Int J Antimicrob Agents 2003;22:1-6.

11. Tritchler D. An algorithm for exact logistic regression. J Amer Statis Assoc 1984;79:709-11.

12. Farrell DJ, Morrissey I, De Rubeis D, Robbins M, Felmingham D. A UK multicentre study of the antimicrobial susceptibility of bacterial pathogens causing urinary tract infections. J Infect 2003;46:94-100.

13. Raz R, Chazan B, Kennes Y, et al. Empiric use of trimethoprimsulfamethoxazole (TMP-SMX) in the treatment of women with uncomplicated urinary tract infections, in a geographical area with a high prevalence of TMP-SMX-resistant uropathogens. Clin Infect Dis 2002;34:1165-9.
14. Karlowsky JA, Jones ME, Thornsberry C, Critchley I, Kelly LJ, Sahm DF. Prevalence of antimicrobial resistance among urinary tract pathogens isolated from female outpatients across the US in 1999. Int J Antimicrob Agents 2001;18:121-7.

15. Richards DA, Toop LJ, Chambers ST, et al. Antibiotic resistance in uncomplicated urinary tract infection: Problems with interpreting cumulative resistance rates from local community laboratories. N Z Med J 2002;115:12-4.

16. Christaens TC, Digranes A, Baerheim A. The relation between sale of antimicrobial drugs and antibiotic resistance in uropathogens in general practice. Scand J Prim Health Care 2002;20:45-9.

17. Health Canada and the Canadian Infectious Disease Society. Controlling antimicrobial resistance. An Integrated action plan for Canadians. Can Commun Dis Rep 1997;(23 Suppl 7):1-32.

18. Magee JT, Pritchard EL, Fitzgerald KA, Dunstan FD, Howard AJ. Antibiotic prescribing and antibiotic resistance in community practice: Retrospective study, 1996-8. BMJ 1999;319:1239-40. 


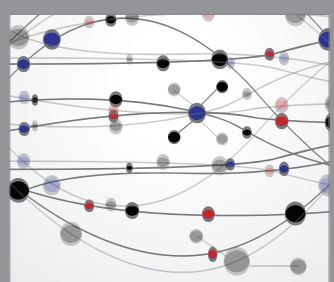

The Scientific World Journal
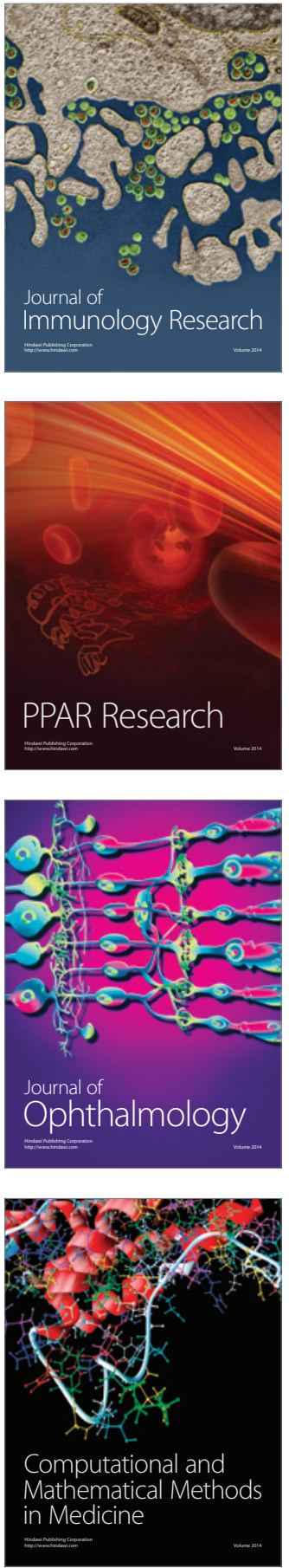

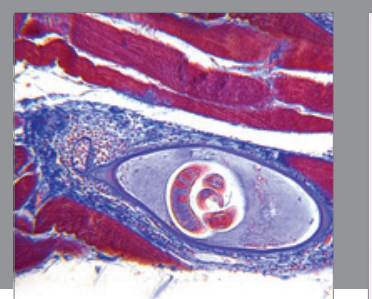

Gastroenterology Research and Practice

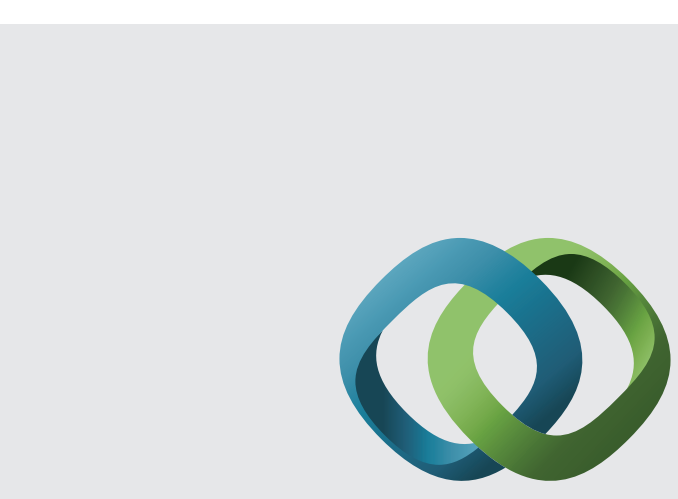

\section{Hindawi}

Submit your manuscripts at

http://www.hindawi.com
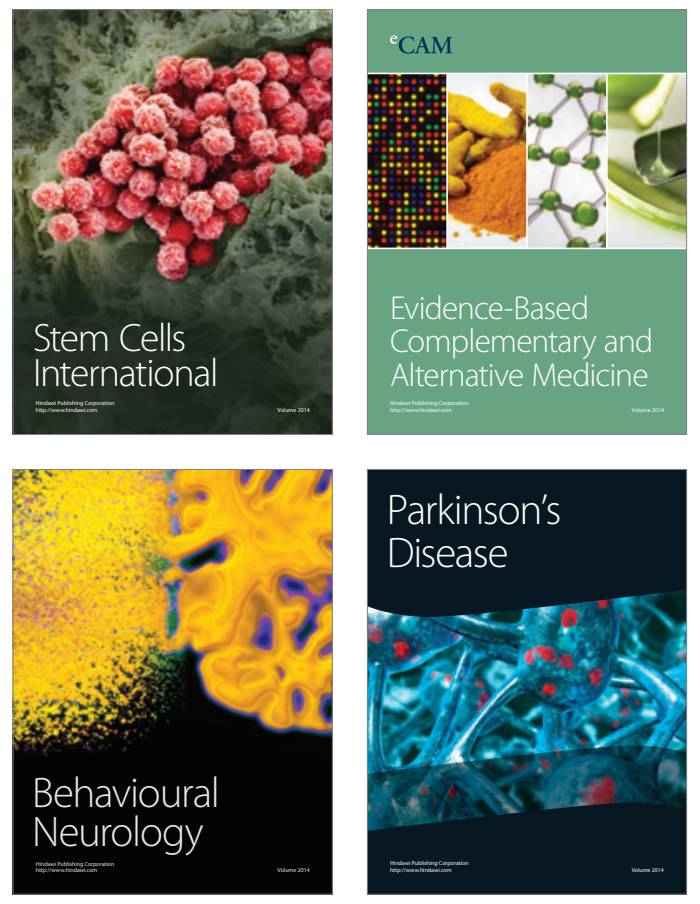
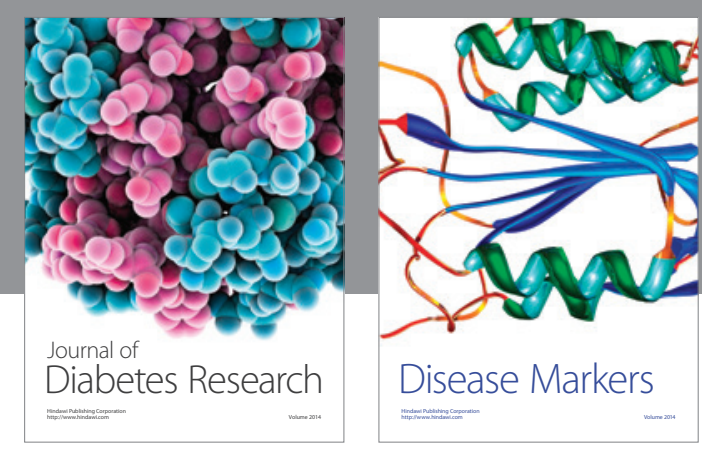

Disease Markers
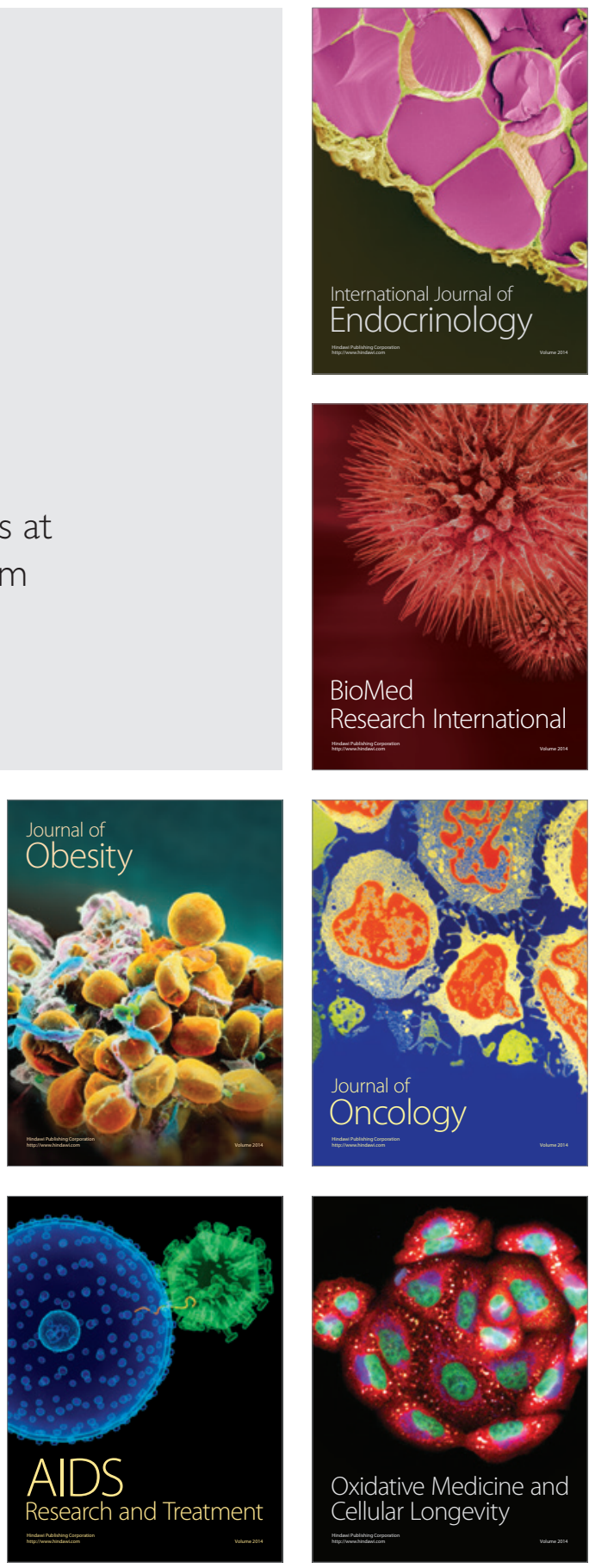